\title{
Altered Total Antioxidant Capacity and Malondialdehyde in Cervical Cancer Patients and Effect of Chemoradiation
}

\author{
Shah SR ${ }^{1}$, Shaheen B Shaikh ${ }^{1}$, Shaheena Yassir ${ }^{1 *}$
}

${ }^{1}$ Department of Biochemistry, Yenepoya Medical College, Yenepoya (Deemed to be) University, Mangalore Karnataka, India

DOI: $10.36348 / \mathrm{sijb} .2021 . \mathrm{v04i2.001}$

| Received: 21.02.2021 | Accepted: 03.03.2021 | Published: 08.03.2021

*Corresponding author: Shaheena Yassir

\section{Abstract}

Background: One of the leading causes of cancer-related death in women worldwide, that causes an enhancednegative impact on quality of life with regard to social and economic burden, is Cervical cancer $(\mathrm{CaCx})$. Early diagnosis and treatment can plummetassociated mortality and morbidity, by hit hard and early approach. Aim and objective: To estimate serum total antioxidant capacity (TAC), and malondialdehyde (MDA) in CaCx patients and analyse their response to chemoradiation. Materials and Methods: Histopathologically proven $\mathrm{CaCx}$ patients $(\mathrm{n}=50)$ and age-matched healthy females $(n=50)$ were recruited in case-control study. Estimation of Serum TAC, and MDA was done in recruited subjects. Both of these parameters wasestimated again after chemoradiationin $\mathrm{CaCx}$ patients, to scrutinize the effect of chemoradiation. In addition, 84\% controls and 34\% cervical cancer patients had a history of Vit. C and E supplementation. Results: The mean \pm SD age of the patients and controls was $43.98 \pm 6.38$ and $31.56 \pm 6.84$ years, respectively. The mean level of serum MDA in the patients was significantly higher as compared with the controls, whereas the mean TAC in the patients was reduced in same comparison. After chemoradiation, serum levels of TAC and MDA, increased and decreased, respectively. Conclusion: These analytical data captured suggests that patients with $\mathrm{CaCx}$ were in oxidative stress because the chosen oxidative parameters, serum MDA were increased, and the defensive TAC was decreased in them. Chemoradiotherapy improved their antioxidant capacity. Further studies are needed to evaluate the concurrent use of antioxidants with chemoradiotherapy for improving the disease prognosis.

Keywords: TAC, MDA, Cervical cancer, oxidative stress.

Copyright $\odot 2021$ The Author(s): This is an open-access article distributed under the terms of the Creative Commons Attribution 4.0 International License (CC BY-NC 4.0) which permits unrestricted use, distribution, and reproduction in any medium for non-commercial use provided the original author and source are credited.

\section{INTRODUCTION}

The third most frequently found cancer among females across the globe is cervical cancer $(\mathrm{CaCx})$. In year 2012, it attributed for 266,000 deaths, $87 \%$ of this occurred in under developed nations, with maximum burden being in India [1, 2]. $\mathrm{CaCx}$ is a prominent cause of cancer related deaths in India, contributing $17 \%$ of deaths due to cancer in women aged in $3^{\text {rd }}$ to $6^{\text {th }}$ decade of life and second commonest cancer [3]. As far as current incidence rates considered, an increase to 225,000 is anticipated by 2025 in India [4,5] with just $42 \%$ chances of surviving [6].The infection with sexually transmitted HPV is accepted as a dominant causal factor for developing $\mathrm{CxCa}$ [7]. HPV $16 \& 18$ being frequent association. Normally, host immunity bugs off majority of the viral infections, those which persist cause cancer in due course of time. Males being carrier of HPV in most cases, infecting and generating the disease in women. Majority of adults are unaware of
HPV infection and risks associated with it [7]. In absence of an effective treatment, its prevention still depends on cervical screening HPV and vaccination[8].The open reading frames ORFs of HPV genome, like E1, E2, E4-E7 are involved in replication and oncogenesisby damaging DNA[9]. However, as per data role of oxidative stress in its development has been disclosed[10]. Generation of free radicals with a decrease in the levels of antioxidants, causes DNA damage, and mutation of tumor suppressor genes, thereby commencing and promoting multi-step carcinogenesis[11]. MDA is toxic outcome of peroxidation of poly unsaturated fatty acid, and is mutagenic to DNA at guanine siteThis product of peroxidation of lipids can possibly lead to progression of uterine cancer $[12,13]$. Therefore the present study was done to assess the oxidative stress in cervical cancer patients in terms of TAC and MDA. And, to see the effect of chemoradiation on these. 


\section{MATERIALS AND METHODS}

A prospective case-control study conducted among diagnosed cases of $\mathrm{CaCx}(n=50)$ and age matched healthy females $(n=50)$ willing to participate in the study. Subjects with any chronic disease like cardio-vascular, respiratory, psychiatric, renal, neurological diseases and those with history of vitamin, mineral supplement, cigarette smoking, and alcohol intake were not recruited for the study. $3 \mathrm{~mL}$ of blood collected from recruited subjects after an informed consent was centrifuged at $3000 \mathrm{rpm}$ for 10 minutes. Separated serum was stored at $-40^{\circ} \mathrm{C}$ till the time of analysis. In addition, blood from patients was drawn after chemoradiation as well for estimation of TAC and MDA. Five cycles of Cisplatin in a weekly dose of $40 \mathrm{~g} / \mathrm{m}^{2}$ was given as chemotherapy, while four fractions of $7 \mathrm{~Gy}$ each brachytherapy constituted radiotherapy. Two applications of radiotherapy were given one week apart.

The TAC and MDA in the collected serum was estimated by using ferric reducing ability of plasma (FRAP) assay by Benzie \& Strain, 1996 [15] and Satoh K method respectively [16].

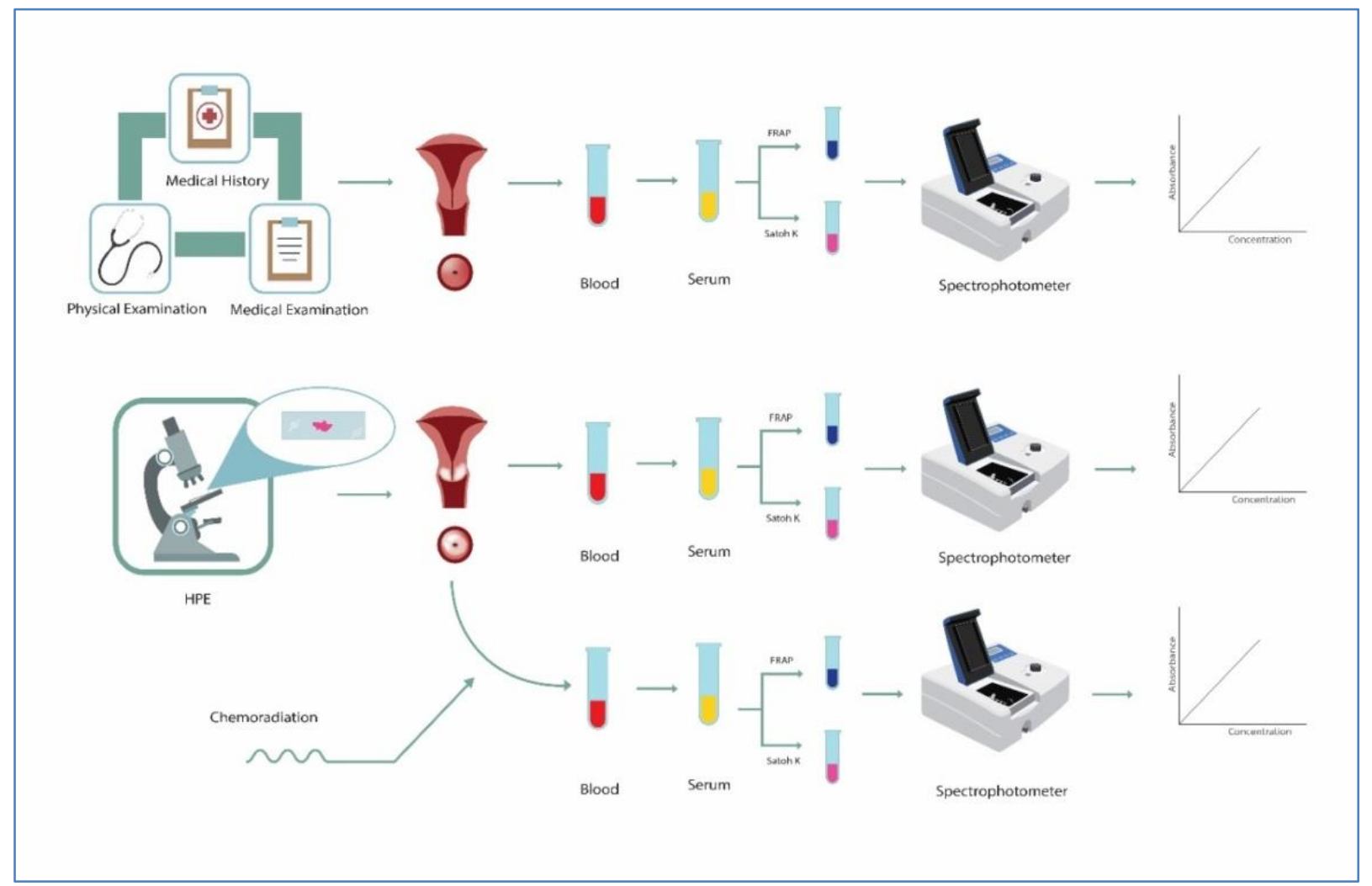

Fig-1: Workflow Chart

\section{STATISTICAL ANALYSIS}

Descriptive and inferential statistical analysis has been carried out in the present study. The Statistical software namely SAS 9.2, SPSS 15.0, Stata 10.1, MedCalc9.0.1, Systat 12.0 and $\mathrm{R}$ environment ver.2.11.1 were used for the analysis of the data and Microsoft word and graphs and tables were generated on Excel. Student t test (two tailed, independent) has been used to find the significance of study parameters. Chi-square test was used to find the significance of study parameters. Pearson correlation between serums MDA \& TAC was performed to find the degree of relationship.

\section{RESULTS}

The study subjects, 50 from each group chosen after exclusion-inclusion criteria were recruited for the study. The mean age in Ca Cx patients was $43.98+6.38$ yrs and in controls, it was $31.56 \pm 6.84$. Among the cases, $50 \%$ were in the fourth to fifth decade of life (Fig.2). The The mean serum $\mathrm{TAC}$ in the $\mathrm{CaCx}$ group was $781.36 \pm 228.88 \mu \mathrm{mol} / \mathrm{L}$ and in control group was $1088.94 \pm 185.07 \mu \mathrm{mol} / \mathrm{L}$ (Table 1) with $74 \%$ of cases and just $6 \%$ controls having values less than $875 \mu \mathrm{mol} / \mathrm{L}$. The TAC in $90 \%$ healthy subject and $26 \%$ of diseasedwas between 875 and $1345 \mu \mathrm{mol} / \mathrm{L}$, while as none of the patients and $4 \%$ of controls had value $>1345 \mu \mathrm{mol} / \mathrm{L}$ (Table 2). The mean value of MDA in the $\mathrm{CaCx}$ and control group was $2.72 \pm 1.01 \mathrm{nmol} / \mathrm{mL}$ and $1.17 \pm 0.52 \mathrm{nmol} / \mathrm{mL}$, respectively (Table 1), with $74 \%$ cases and only $8 \%$ of controls having $>2.00$ $\mathrm{nmol} / \mathrm{ml}$. The difference in both the parameters across groups was significant $(\mathrm{p}<0.001)$. A statistically significant negative correlation was found between $\mathrm{Sr}$. TAC and MDA $(r=-0.278, p=0.050)$ in cervical cancer patients, while it was insignificant in healthy controls (Table 3). A statistically significant increase in Sr TAC 
$(\mathrm{p}=0.018)$ and a decrease in Sr MDA $(\mathrm{p}<0.001)$ was observed after chemoradiation in cervical cancer patients (Table 4). In addition, $84 \%$ controls and $34 \%$ cervical cancer patients had a history of Vit. C and E supplementation. But the levels were not measured.

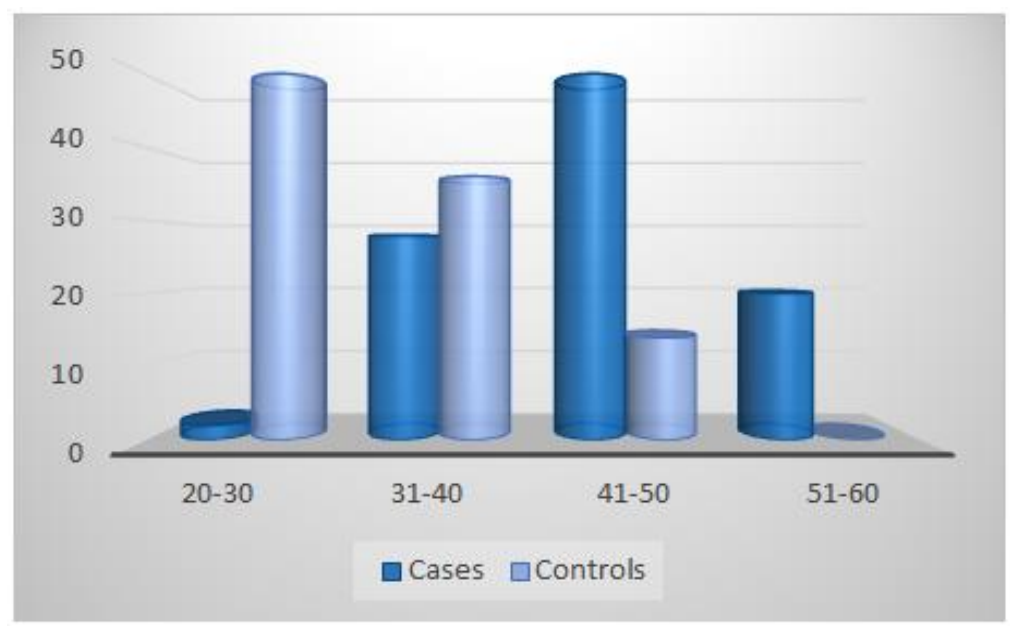

Fig-2: Bar diagram showing age distribution in study group

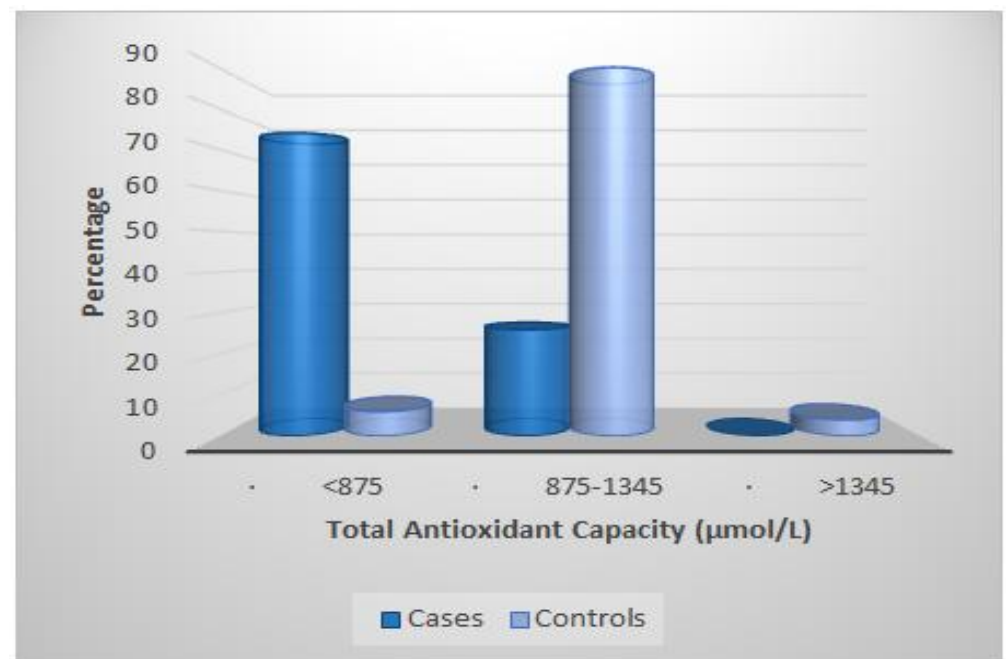

Fig-3: Bar diagram showing Sr. TAC in study groups

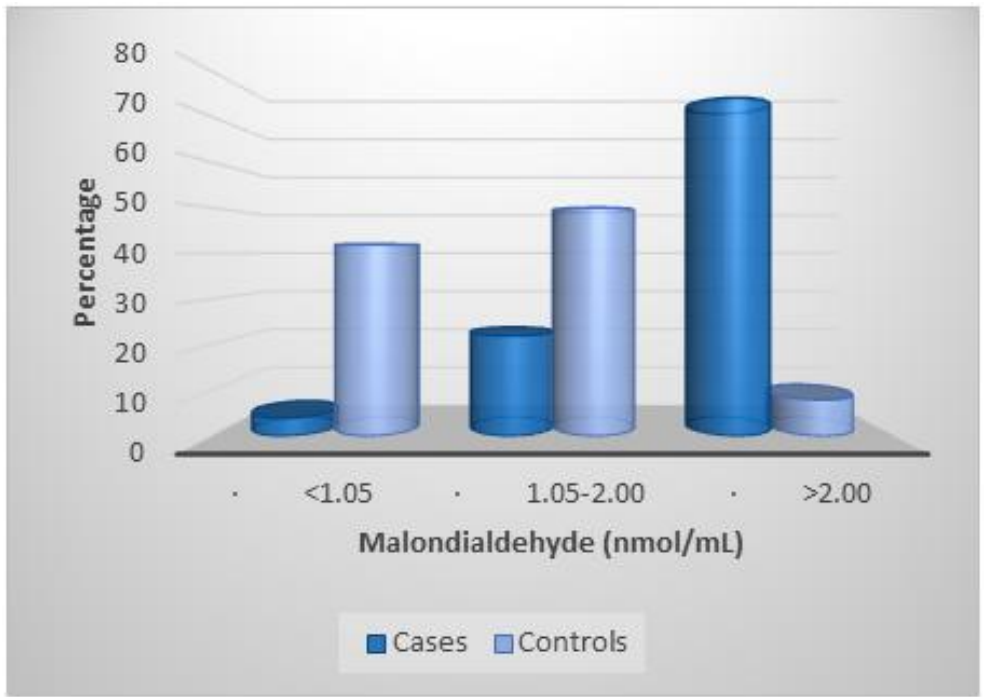

Fig-4: Bar diagram showing MDA levels in study groups. 
Table-1: Mean comparison of study variables in cases and controls studied

\begin{tabular}{|l|l|l|l|}
\hline Serum & Cases & Controls & P value \\
\hline Total Antioxidant Capacity & $781.36 \pm 228.88$ & $1088.94 \pm 185.07$ & $<0.001$ \\
\hline Malondialdehyde & $2.72 \pm 1.01$ & $1.17 \pm 0.52$ & $<0.001$ \\
\hline \multicolumn{2}{|l|}{$p<0.001=$ statistically significant }
\end{tabular}

Table-2: Comparison of Serum TAC and MDA in two groups studied.

\begin{tabular}{|c|c|c|c|c|c|}
\hline \multirow[t]{2}{*}{ Variables } & \multicolumn{2}{|c|}{$\begin{array}{l}\text { Cases } \\
(n=50)\end{array}$} & \multicolumn{2}{|c|}{$\begin{array}{l}\text { Controls } \\
(\mathbf{n}=50)\end{array}$} & \multirow[t]{2}{*}{ P value } \\
\hline & No & $\%$ & No & $\%$ & \\
\hline \multicolumn{6}{|c|}{ Total Antioxidant Capacity $(\mu \mathrm{mol} / \mathrm{L})$} \\
\hline$<875$ & 37 & 74.0 & 3 & 6.0 & \multirow[t]{3}{*}{$<0.001$} \\
\hline $875-1345$ & 13 & 26.0 & 45 & 90.0 & \\
\hline$>1345$ & 0 & 0.0 & 2 & 4.0 & \\
\hline \multicolumn{6}{|c|}{ Malondialdehyde $(\mathrm{nmol} / \mathrm{ml})$} \\
\hline$<1.05$ & 2 & 4.0 & 21 & 42.0 & \multirow[t]{3}{*}{$<0.001^{* *}$} \\
\hline $1.05-2.00$ & 11 & 22.0 & 25 & 50.0 & \\
\hline$>2.00$ & 37 & 74.0 & 4 & 8.0 & \\
\hline
\end{tabular}

Table-3: Pearson correlation of Serum TAC with MDA

\begin{tabular}{|l|l|l|l|l|}
\hline & \multicolumn{2}{|l|}{ Cases } & \multicolumn{2}{l|}{ Controls } \\
\cline { 2 - 5 } & r value & P value & r value & P value \\
\hline Total Antioxidant Capacity vs Malondialdehyde & -0.278 & 0.050 & 0.158 & 0.272 \\
\hline
\end{tabular}

Table-4: Comparison of TAC and MDA in cervical cancer patients before and after chemoradiation

\begin{tabular}{|l|l|l|l|}
\hline & \multicolumn{2}{|l|}{ Cervical cancer } & \multirow{2}{*}{ p-value } \\
\cline { 2 - 3 } & Before CT & After CT & \\
\hline Total Antioxidant Capacity $(\mu \mathrm{mol} / \mathrm{L})$ & $781.36 \pm 228.88$ & $917+358$ & 0.018 \\
\hline Malondialdehyde $(\mathrm{nmol} / \mathrm{mL})$ & $2.72 \pm 1.01$ & $2.5+0.92$ & $<0.001$ \\
\hline
\end{tabular}

$\mathrm{p}<0.001=$ statistically significant

\section{DISCUSSION}

Cervical cancer is the leading cause of cancer mortality in India, accounting for $17 \%$ of all cancer deaths among women in third to sixth decade of life [17]. The 5-year survival rate in <50years of age is $76 \%$, and $72.5 \%$ had squamous cell carcinoma [18]. The associated morbidity, mortality and the cost to society due to $\mathrm{CxCa}$, has made it important public healthcare challenge. The objective of identifying risk factors, early diagnosis and treatment is to reduce the associated morbidity and mortality. Oxidative stress as a causal factor in cervical cancer has been explored extensively. The mutations and unrestricted multiplication of cells through a series of events lead to the development of cancer. Recent published data set up oxidative stress and its associated damage contributing towards initiation and progression of cancer and its link with signalling of oncogenes $[19,20]$. This study was designed to quantitate and compare serum TAC and MDA in diagnosed cases of cervical cancer and normal healthy females. And to assess the effect of treatment in the form of chemoradiation on these parameters in cancer patients. These two parameters were chosen to evaluate the oxidative stress in cervical patients. Role of oxidative stress using different parameters in different cancers in different stages has been extensively studied in recent times.

One of the final and harmful products of lipid peroxidation is MDA, which has been used as a biomarker in many platforms to estimate the depth of oxidative stress and cell damage by its ability to bind to the proteins at free amino groups, nucleic acids [21, 22].The quantitated levels of MDA in our study was significantly higher $(\mathrm{p}<0.001)$ in $\mathrm{CaCx}$ serum compared to the normal one. Similar increased levels of circulating MDA was found by Grace et al., to assess the extent of lipid peroxidation [23]. This was attributed to accelerated lipid peroxidation parallel to compromised defensive antioxidant mechanism in $\mathrm{CaCx}$ patients. As per Naidu et al. the elevated serum MDA levels in their patients was a possible cause of progression of $\mathrm{CaCx} .[10]$ With the similar results, Demirici et al. explained that an increased MDA levels and DNA damage maybe a result of oxidative damage, which further leads to mutagenesis, cell death and carcinogenesis. [24]. Similarly, a raised MDA in CIN cases as compared to control group has been reported $[25,26]$. 
The intermediary product of different metabolic processes in subcelluar organelles along with other processes like oxidation of fatty acids are reactive oxygen species (ROS), which are secreted in minute quantity of picomoles. The unrestricted amounts are taken care of by the antioxidant present. Imbalance in this system leads to increase in ROS, thereby causing chronic diseases like cancer, diabetes mellitus etc. increased free radicals results in malignancy and metastasis [27, 28]. Both the bigger molecules like catalase, SOD etc and the smaller ones like carotenoids, vit. $\mathrm{C}$ and $\mathrm{E}$ have a capacity to control the redox balance in malignant cells. Diseases can be prevented by dietary antioxidants [29].Therefore, the relationship between a decreased antioxidant level and malignancy and premalignant conditions has been evaluated by researchers at various strata. The defensive antioxidant system in human bodies depends upon the intake in diet and endogenous formation [28].

The TAC measures the antioxidant potential of all the antioxidants in the serum, so we chose TAC estimation in our study. It was found to be decreased $(\mathrm{p}<0.001)$ in patients as compared to controls like that of Demirici et al., and Rong et al., [24,30]. In addition, Kim et al. and Lee et al., associated the lower levels of TAC in CIN patients as compared to that of healthy females $[25,26]$.

One more finding of our study was opposite drift in Serum TAC and MDA in patients of cervical cancer post chemoradiation in comparison to pretreatment levels. Standard cancer treatment by radiotherapy exerts its effect by generating local oxidative stress leading to damaging the cellular proteins, DNA, lipids and governs an abnormal cell signalling, this results in cancer cell death [31]. As per Sun L et al. the total antioxidant capacity of whole blood decreases in proportion to the doses of irradiation given [32].

\section{CONCLUSION}

Our study demonstrated dysregulated levels of serum TAC and MDA levels in cervical cancer compared to healthy females. An imbalance in these parameters sets in oxidative stress and may play a role in initiation and progression of cancer. Further, the balance of oxidant-antioxidant system shifts towards the improvement in the antioxidant status after chemoradiation. Many more studies at various platforms in a larger cohort of cases extended over longer time are required to evaluate effects of antioxidant supplements on cancer initiation and metastasis.

\section{Limitations}

The sample size and the time period taken was small and results cannot be used as a conclusive evidence if concurrent antioxidant supplements can improve outcome after chemoradiation.

\section{Declaration of Conflicting Interests}

The author(s) declared no potential conflicts of interest with respect to the research, authorship, and/or publication of this article.

\section{ACKNOWLEDGMENT}

We are thankful to the patients who despite being in pain and distress gave their consent to conduct this study. We acknowledge Mr. Furqan Amin Khan and Mr. Haris M Shah for designing the graphics which were used in the manuscript.

\section{REFERENCES}

1. Ferlay, J., Soerjomataram, I., Dikshit, R., Eser, S., Mathers, C., Rebelo, M., \& Bray, F. (2015). Cancer incidence and mortality worldwide: sources, methods and major patterns in GLOBOCAN 2012. International journal of cancer, 136(5), E359-E386.

2. Campos, N. G., Tsu, V., Jeronimo, J., Regan, C., Resch, S., Clark, A., \& Kim, J. J. (2019). Health impact of delayed implementation of cervical cancer screening programs in India: A modeling analysis. International journal of cancer, 144(4), 687-696.

3. Kumar, D., Dey, T., Bansal, P., Srinivasa, G. Y., \& Rai, B. (2020). Sociodemographic and clinical profile of geriatric patients with cervical cancerAn audit from a tertiary cancer center in India. Journal of Family Medicine and Primary Care, 9(3), 1528.

4. Sreedevi, A., Javed, R., \& Dinesh, A. (2015). Epidemiology of cervical cancer with special focus on India. International journal of women's health, 7, 405 .

5. Krishnan, S., Madsen, E., Porterfield, D., \& Varghese, B. (2013). Advancing cervical cancer prevention in India: implementation science priorities. The oncologist, 18(12), 1285.

6. Catarino, R., Petignat, P., Dongui, G., \& Vassilakos, P. (2015). Cervical cancer screening in developing countries at a crossroad: Emerging technologies and policy choices. World journal of clinical oncology, 6(6), 281.

7. Braaten, K. P., \& Laufer, M. R. (2008). Human papillomavirus (HPV), HPV-related disease, and the HPV vaccine. Reviews in obstetrics and gynecology, 1(1), 2.

8. Hu, Z., \& Ma, D. (2018). The precision prevention and therapy of HPV- related cervical cancer: new concepts and clinical implications. Cancer medicine, 7(10), 5217-5236.

9. Burd, E. M. (2003). Human papillomavirus and cervical cancer. Clinical microbiology reviews, 16(1), 1-17.

10. Naidu, M. S. K., Suryakar, A. N., Swami, S. C., Katkam, R. V., \& Kumbar, K. M. (2007). Oxidative stress and antioxidant status in cervical 
cancer patients. Indian Journal of Clinical Biochemistry, 22(2), 140-144.

11. Georgescu, S. R., Mitran, C. I., Mitran, M. I., Caruntu, C., Sarbu, M. I., Matei, C., ... \& Popa, M. I. (2018). New insights in the pathogenesis of HPV infection and the associated carcinogenic processes: the role of chronic inflammation and oxidative stress. Journal of immunology research, 2018.

12. Barrera, G. (2012). Oxidative stress and lipid peroxidation products in cancer progression and therapy. International Scholarly Research Notices, 2012.

13. Jelić, M., Mandić, A., Kladar, N., Sudji, J., Božin, B., \& Srdjenović, B. (2018). Lipid peroxidation, antioxidative defense and level of 8-hydroxy-2deoxyguanosine in cervical cancer patients. Journal of medical biochemistry, 37(3), 336-345.

14. Cervellati, C., Romani, A., Seripa, D., Cremonini, E., Bosi, C., Magon, S., ... \& Zuliani, G. (2014). Systemic oxidative stress and conversion to dementia of elderly patients with mild cognitive impairment. BioMed research international, 2014.

15. Benzie, I. F., \& Strain, J. J. (1996). The ferric reducing ability of plasma (FRAP) as a measure of "antioxidant power": the FRAP assay. Analytical biochemistry, 239(1), 70-76.

16. Sotoh, K. (1978). Serum lipid peroxide in cerebrovascular disorders determined by a new colorimetric method. Clin Chim Acta, 90, 37-43.

17. Bobdey, S., Sathwara, J., Jain, A., \& Balasubramaniam, G. (2016). Burden of cervical cancer and role of screening in India. Indian journal of medical and paediatric oncology: official journal of Indian Society of Medical \& Paediatric Oncology, 37(4), 278.

18. Balasubramaniam, G., Gaidhani, R. H., Khan, A., Saoba, S., Mahantshetty, U., \& Maheshwari, A. Survival rate of cervical cancer from a study conducted in India. Indian Journal of Medical Sciences, 1-10.

19. Klaunig, J.E. (2018). Oxidative stress and cancer. Curr pharm des. Nov 1;24(40):4771-8.

20. Gill, J. G., Piskounova, E., \& Morrison, S. J. (2016, January). Cancer, oxidative stress, and metastasis. In Cold Spring Harbor symposia on quantitative biology (Vol. 81, pp. 163-175). Cold Spring Harbor Laboratory Press.

21. Macotpet, A., Suksawat, F., Sukon, P., Pimpakdee, K., Pattarapanwichien, E., Tangrassameeprasert, R., \& Boonsiri, P. (2013). Oxidative stress in cancer-bearing dogs assessed by measuring serum malondialdehyde. BMC veterinary research, 9(1), 1-6.

22. Rašić, I., Rašić, A., Akšamija, G., \& Radović, S. (2018). The relationship between serum level of malondialdehyde and progression of colorectal cancer. Acta Clinica Croatica, 57(3.), 411-416.

23. Nirmala, J. G., \& Narendhirakannan, R. T. (2011). Detection and genotyping of high-risk HPV and evaluation of anti-oxidant status in cervical carcinoma patients in Tamil Nadu State, India-a case control study. Asian Pacific Journal of Cancer Prevention, 12(10), 2689-2695.

24. Demirci, S., Ozsaran, Z., Celik, H. A., Aras, A. B., \& Aydin, H. H. (2011). The interaction between antioxidant status and cervical cancer: a case control study. Tumori Journal, 97(3), 290-295.

25. Kim, J. W., Choi, E. K., Lim, J. H., Kim, Y. T., Kim, D. K., Lee, Y. C., ... \& Chung, H. Y. (2002). Antioxidant system and oxidative stress in uterine cervical neoplasia of Korean women. Korean Journal of Obstetrics and Gynecology, 45(1), 145152.

26. Lee, G. J., Chung, H. W., Lee, K. H., \& Ahn, H. S. (2005). Antioxidant vitamins and lipid peroxidation in patients with cervical intraepithelial neoplasia. Journal of Korean medical science, 20(2), 267.

27. George, S., \& Abrahamse, H. (2020). Redox Potential of Antioxidants in Cancer Progression and Prevention. Antioxidants, 9(11), 1156.

28. Kurutas, E. B. (2015). The importance of antioxidants which play the role in cellular response against oxidative/nitrosative stress: current state. Nutrition journal, 15(1), 1-22.

29. Nimse SB, Pal D. Free radicals, natural antioxidants, and their reaction mechanisms. RSC advances. 2015;5(35):27986-8006.

30. Wu, R., Feng, J., Yang, Y., Dai, C., Lu, A., Li, J., ... \& Du, X. B. (2017). Significance of serum total oxidant/antioxidant status in patients with colorectal cancer. PLoS One, 12(1), e0170003.

31. Serbanescu, G. L., Gruia, M. I., Bara, M., \& Anghel, R. M. (2017). The evaluation of the oxidative stress for patients receiving neoadjuvant chemoradiotherapy for locally advanced rectal cancer. Journal of medicine and life, 10(1), 99.

32. Sun, L., Inaba, Y., Sato, K., Hirayama, A., Tsuboi, K., Okazaki, R., \& Moritake, T. (2018). Dosedependent decrease in anti-oxidant capacity of whole blood after irradiation: A novel potential marker for biodosimetry. Scientific reports, 8(1), 18 . 